\title{
Informed consent in refractive surgery: in-person vs telemedicine approach
}

This article was published in the following Dove Press journal:

Clinical Ophthalmology

\author{
Steven C Schallhorn ${ }^{1-3}$ \\ Stephen J Hannan² \\ David Teenan ${ }^{2}$ \\ Martina Pelouskova ${ }^{2}$ \\ Julie M Schallhorn ${ }^{1,4}$ \\ 'Department of Ophthalmology, \\ University of California, San Francisco, \\ CA, USA; ${ }^{2}$ Optical Express, Glasgow, \\ UK; ${ }^{3}$ Carl Zeiss Meditec, Dublin, \\ CA, USA; ${ }^{4}$ F.I. Proctor Foundation, \\ University of California, San Francisco, \\ CA, USA
}

Correspondence: Steven C Schallhorn I 730 Caminito Prenticia, San Diego, CA 92131 , USA

Tel +l 8584556800

Email scschallhorn@yahoo.com
Purpose: The aim of this study was to compare the quality of consent process in refractive surgery between patients who had a preoperative consent discussion with the surgeon using a telemedicine approach and those who had a face-to-face discussion.

Methods: Patients treated between January and December 2017 (8,184 laser vision correction [LVC] and 3,754 refractive lens exchange [RLE] patients) that attended day 1 and 1-month postoperative visit were retrospectively reviewed. Preoperative consent preparation included a consultation with an optometrist, observation of an educational video, and written information. Patients then selected either a face-to-face appointment with their surgeon (in-clinic group) or a telemedicine appointment (remote group) for their consent discussion, according to their preference. Patient experience questionnaire and clinical data were included in a multivariate model to explore factors associated with consent quality.

Results: Prior to surgery, $80.1 \%$ of LVC and $47.9 \%$ of RLE patients selected remote consent. Of all LVC patients, $97.5 \%$ of in-clinic and $98.3 \%$ of remote patients responded that they were adequately consented for surgery $(P=0.04)$. Similar percentages in the RLE group were $97.6 \%$ for in-clinic and $97.9 \%$ for remote patients $(P=0.47)$. In a multivariate model, the major predictor of patient's satisfaction with the consent process was postoperative satisfaction with visual acuity, responsible for $80.4 \%$ of variance explained by the model. Other significant contributors were postoperative visual phenomena and dry eyes, difficulty with night driving, close-up and distance vision, postoperative uncorrected distance visual acuity, change in corrected distance visual acuity, and satisfaction with the surgeon's approach. The type of consent (remote or inclinic) had no impact on patient's perception of consent quality in the regression model.

Conclusion: The majority of patients opted for telemedicine-assisted consent. Those who chose it were equally satisfied as those who had a face-to-face meeting with their surgeon. Dissatisfaction with surgical outcome was the major factor affecting patient's perception of consent quality, regardless of the method of their consent.

Keywords: informed consent, telemedicine, refractive surgery, LASIK, photorefractive keratectomy, refractive lens exchange

\section{Introduction}

Telemedicine is defined as the use of telecommunication and information technology to provide clinical health care from a distance. ${ }^{1}$ With improvements in technology, Internet, and transfer of information, telemedicine has become established in numerous areas of medicine. This includes multiple areas of health care delivery: consenting, achieving a diagnosis, instituting treatment, disease prevention, and medical research. ${ }^{1-3}$ In ophthalmology, telemedicine (or "teleophthalmology") has been used mainly for screening for glaucoma, cataract, or retinal diseases, providing patients in rural and remote areas with improved access to eye care. ${ }^{2,4-6}$ There have also been some recent 
reports of using teleophthalmology as a therapeutic, rather than just diagnostic tool (eg, teleophthalmology navigated retinal laser therapy), which could have great potential for the future. ${ }^{7}$

In one of our previous publications, we discussed the consent process for elective refractive surgery, the role of the treating surgeon in the consenting process, and examined if meeting the surgeon prior to the surgery or on the day of surgery affects the patient's perception of consent quality. ${ }^{8}$ We also explored how the consent process can be enhanced with the use of different tools such as video consent, written information, and the involvement of medical personnel other than the treating surgeon. ${ }^{8}$ Since our last publication, new UK General Medical Council guidelines were published and came into effect in June 2016. These require doctors performing cosmetic or refractive interventions to discuss the procedure with their patient ahead of the day of surgery. ${ }^{9}$ This prompted us to change our consenting approach: each patient is required to discuss the procedure with their treating surgeon prior to the day of surgery. Patients have an option to either discuss the procedure remotely (telemedicine) or to have a face-to-face meeting with their surgeon prior to the day of surgery. Each patient, whether they elect to speak to their surgeon via a telemedicine or face-to-face meeting approach, has to undergo a face-to-face examination on the day of surgery prior to any procedure taking place. During this examination, the treating surgeon and patient complete the informed consent process. The aim of this study was to investigate whether these two methods of consenting (remote or in-clinic) have an impact on the patient's perception of consent quality.

\section{Patients and methods}

All patients provided informed consent to undergo refractive surgery (LASIK, photorefractive keratometry [PRK], or refractive lens exchange [RLE]). As a part of their consent process, all patients involved in the study agreed for their data to be used (without patient's identifiers) for statistical analysis and research. The study was deemed exempt from full review by the Committee on Human Research at the University of California, San Francisco because it used only retrospective, de-identified patient data, and followed the principles of the Declaration of Helsinki.

Clinical data and patient questionnaire outcomes were exported from Optical Express electronic medical records for all patients who underwent laser vision correction (LVC) or RLE (corrected distance visual acuity [CDVA] not worse than 20/40) between January and December 2017, attended day 1 and 1-month postoperative follow-up visit, and completed a questionnaire.

Patients first underwent a preoperative consultation with an experienced refractive optometrist in their local clinic, which involved clinical examination, discussion, and diagnostic measurements. The refractive optometrist first assessed the patient's medical and ocular history, occupation, hobbies, and general expectations from refractive surgery. The clinical examination involved a manifest refraction, cycloplegic refraction, uncorrected distance visual acuity (UDVA) and CDVA, external ocular exam, ocular motility, confrontational visual fields, biomicroscopic exam, dilated fundoscopy, and diagnostic scans (corneal topography: Pentacam; Oculus Inc., Arlington, WA, USA; wavefront aberrometry: iDesign Advanced Wave Scan System; Johnson \& Johnson Vision Care, Inc, Jacksonville, FL, USA; noncontact tonometry/autorefraction).

Based on the consultation, the optometrist made a preliminary determination of whether the patient met all the suitability criteria for refractive surgery and discussed the most appropriate procedure (LASIK, PRK, or RLE). The optometrist then discussed the benefits of the proposed surgery, possible complications, side effects, and postoperative expectations, and answered all the patient's questions. The patient was also provided written information consisting of the informed consent document, information about the procedure, preoperative preparation, and postoperative aftercare.

All patients watched an educational video, which reiterated all the points discussed with the optometrist. At the conclusion of the video, the patient and the optometrist completed an electronic signature section within the Electronic Medical Records system to confirm the patient's understanding of the proposed procedure, potential risks, and range of associated outcomes in addition to the benefits and alternatives. RLE candidates had a detailed discussion about intraocular lens types and their possible side effects and underwent further diagnostic tests (biometry for lens calculation: IOLMaster; Carl Zeiss Meditec AG, Jena, Germany; retinal optical coherence tomography: Cirrus 4000/500 OCT; Carl Zeiss Meditec AG; and specular microscopy: SP 2000P specular microscope; Topcon Europe BV, Tokyo, Japan).

All patients then had an option to either meet their surgeon prior to the day of surgery in person ("in-clinic" group) or to arrange a telephone discussion with the surgeon ("remote" group). Patient's choice determined the type of consent, but there was a small group of patients with certain conditions that were required to attend in-clinic consent, and these patients were excluded from this study. In-clinic consent 
was necessary in all patients (RLE and LVC) with significant corneal scars (CDVA $\leq 20 / 25$ ), corneal dystrophy (Fuchs, guttata, map-dot-fingerprint dystrophy, etc), family history of keratoconus, and any suspicious corneal shape (superiorinferior keratometry difference on Pentacam saggital map [4 mm diameter] >1.4 D or any other signs of abnormal or irregular topography). Additionally, for RLE patients, it was mandatory to attend in-clinic consent if they: were younger than 50 years with myopia $>6.0 \mathrm{D}$, were younger than 40 years (regardless of the refractive error), had low distance prescription presbyopes (defined as UDVA of 20/25 or better in each eye), and had retinal pathology reducing CDVA to $\leq 20 / 25$ (eg, signs of age-related macular degeneration, drusen, epiretinal membrane, etc).

All patients who participated in an in-clinic consent had a discussion and ophthalmic examination performed by their surgeon on the day of their consultation and a further examination performed on the day of surgery. All patients in the remote group had a discussion with the surgeon over the phone and an ophthalmic examination performed by the treating surgeon on the day of surgery. Prior to the remote discussion, surgeons had access to the patient's electronic file and reviewed outcomes of all scans and measurements obtained by the optometrist in their local clinic. In both cases (in-clinic and remote), patients were encouraged to have their consent discussion at least 7 days prior to surgery, and if this was not possible, a minimum 48-hour reflection period was required. Each step of the consent process (discussion with an optometrist, video consent, discussion with the surgeon) culminated in signing an electronic declaration, where the patient confirmed understanding all main points of the discussion. Patient who had a remote consent discussion received a web link asking them to confirm that the discussion took place.

Except for patients with known conditions described above, patients could choose between the two types of consent (in-clinic or remote); however, they were always encouraged to meet their surgeon ahead of the day of surgery and this appointment did not incur any extra cost.

Postoperatively, patients were scheduled for 1-day, 1-week, and 1-month follow-up visits were they were clinically examined and completed a postoperative questionnaire. The methodology of obtaining the questionnaire has been previously described. ${ }^{8}$ The questionnaire was strictly confidential, and patients were informed that their responses were not made available to the treating surgeon and were not accessible to any clinic personnel. All questions from the patient questionnaire used for statistical analysis are listed in Table 1.

\section{Statistical analysis}

All calculations and statistical analysis were performed using SAS 9.3 (SAS Institute Inc., Cary, NC, USA) and Microsoft Office Excel 11.0 (Microsoft Corporation, Redmond, WA, USA) software. Preoperative and 1-month postoperative data between in-clinic and remote groups of patients were compared using an unpaired $t$-test and a chi-squared test was applied for the comparison of percentages.

A multivariate regression model was developed to find independent predictors of the outcomes of question 3 (Table 1): "Do you feel you were properly consented for surgery?" Variables included in the regression model were patients demographics (age, gender), preoperative and postoperative clinical data (visual acuity, refractive error), questionnaire outcomes (Table 1), type of consent (in-clinic vs remote), as well as the number of days between the consent appointment and surgery day. The model was developed using a stepwise generalized linear approach. Detailed steps in model creation have been previously described. ${ }^{8}$

\section{Results}

Of all patients, $19.9 \%$ of LVC patients and $52.1 \%$ of RLE patients preferred to meet their treating surgeon ahead of the day of surgery, whereas $80.1 \%$ of LVC patients and $47.9 \%$ of RLE patients opted for a remote consent discussion. Tables 2 (LVC) and 3 (RLE) compare preoperative and 1-month postoperative clinical parameters between in-clinic and remote groups of patients. Patients who opted to meet their treating surgeon ahead of the day of surgery were slightly older and tended to have higher preoperative myopic sphere, higher cylinder, and slightly worse preoperative CDVA (Tables 2 and 3). As expected (due to higher levels of preoperative ametropia), most of the mean postoperative outcomes were worse for patients with inclinic consent.

\section{Postoperative day I questionnaire}

On the first postoperative day, $99.6 \%$ of in-clinic LVC patients and $99.3 \%$ of remote patients $(P=0.21)$ responded by confirming that they were either satisfied or very satisfied with the surgeon's care (question 1, Table 1). In the RLE group, these percentages were $99.5 \%$ and $99.6 \%$ for in-clinic and remote groups, respectively $(P=0.82)$.

Most of the patients in the LVC group $(98.9 \%$ of in-clinic patients vs $99.1 \%$ of remote patients; $P=0.64$ ) and RLE group (99.1\% in-clinic and $99.4 \%$ remote; $P=0.30$ ) were satisfied or very satisfied that their surgeon answered all of their questions (question 2, Table 1). 
Table I Patient experience questionnaire

\begin{tabular}{|c|}
\hline Postoperative day I questionnaire \\
\hline $\begin{array}{l}\text { Question I. Overall how satisfied are you with the care that was provided by the surgeon? } \\
\text { (I= very satisfied, } 2=\text { satisfied, } 3=\text { neither, } 4=\text { dissatisfied, } 5=\text { very dissatisfied) }\end{array}$ \\
\hline $\begin{array}{l}\text { Question } 2 \text {. Overall how satisfied are you that the surgeon answered all of your questions? } \\
\text { ( } I=\text { very satisfied, } 2=\text { satisfied, } 3=\text { neither, } 4=\text { dissatisfied, } 5=\text { very dissatisfied })\end{array}$ \\
\hline One-month postoperative questionnaire \\
\hline $\begin{array}{l}\text { Question } 3 \text {. Do you feel you were properly consented for surgery? } \\
(I=\text { yes, } 2=\text { no) }\end{array}$ \\
\hline $\begin{array}{l}\text { Question } 4 \text {. Thinking about your vision during the last week, how satisfied are you with your vision (without the use of glasses or contact lenses)? } \\
\text { (I= very satisfied, } 2 \text { = satisfied, } 3=\text { neither, } 4=\text { dissatisfied, } 5=\text { very dissatisfied) }\end{array}$ \\
\hline $\begin{array}{l}\text { Question } 5 . \text { Would you recommend vision correction surgery to your friends and relatives? } \\
(\mathrm{I}=\text { yes, } 2=\text { no) }\end{array}$ \\
\hline $\begin{array}{l}\text { Question } 6 . \text { Think about your vision during the last week. } \\
\text { Please rate the degree of difficulty you experienced with: } \\
\text { - starburst } \\
\text { - glare } \\
\text { - halos } \\
\text { - ghosting/double vision } \\
\text { - dry eyes } \\
\text { (Measured on a discrete scale from I= no difficulty to } 7=\text { severe difficulty) }\end{array}$ \\
\hline $\begin{array}{l}\text { Question } 7 \text {. Because of your eyesight, how much difficulty do you have with driving at night? } \\
\text { (I= no difficulty, } 2=\text { a little difficulty, } 3=\text { moderate difficulty, } 4=\text { a lot of difficulty, } 5=\text { never try to do this because of my vision, } 6=\text { never do this for } \\
\text { other reasons) }\end{array}$ \\
\hline $\begin{array}{l}\text { Question 8. Because of your eyesight, how much difficulty do you have in doing work or hobbies that require you to see well up close, such as } \\
\text { cooking, fixing things around the house, sewing, using hand tools, or working with a computer? } \\
\text { (I= no difficulty, } 2=\text { a little difficulty, } 3=\text { moderate difficulty, } 4=\text { a lot of difficulty, } 5=\text { never try to do this because of my vision, } 6=\text { never do this for } \\
\text { other reasons) }\end{array}$ \\
\hline $\begin{array}{l}\text { Question 9. Because of your eyesight, how much difficulty do you have in taking part in active sports or other outdoor activities that you enjoy } \\
\text { (like hiking, swimming, aerobics, team sports, or jogging)? } \\
\text { (I= no difficulty, } 2=\text { a little difficulty, } 3=\text { moderate difficulty, } 4=\text { a lot of difficulty, } 5=\text { never try to do this because of my vision, } 6=\text { never do this for } \\
\text { other reasons) }\end{array}$ \\
\hline
\end{tabular}

Table 2 Preoperative and I-month postoperative clinical outcomes of laser vision correction patients

\begin{tabular}{|c|c|c|c|}
\hline \multirow[t]{2}{*}{ Clinical/demographic variable } & \multicolumn{2}{|l|}{ Consent type } & \multirow[t]{2}{*}{$P$-value } \\
\hline & In-clinic & Remote & \\
\hline $\begin{array}{l}\text { Number of patients } \\
\text { Female/male ratio } \\
\text { Age }^{\mathrm{a}}\end{array}$ & $\begin{array}{l}1,626 \\
45.8 \% / 54.2 \% \\
34.4 \pm 10.8(18-66)\end{array}$ & $\begin{array}{l}6,558 \\
47.4 \% / 52.6 \% \\
33.8 \pm 10(18-66)\end{array}$ & $\begin{array}{l}- \\
0.23 \\
0.03\end{array}$ \\
\hline $\begin{array}{l}\text { Preoperative data }^{\mathbf{a}} \\
\text { Sphere } D\end{array}$ & & & \\
\hline $\begin{array}{l}\text { Myopic sphere } \\
\text { Hyperopic sphere } \\
\text { Range } \\
\text { Cylinder, D } \\
\text { CDVA, logMAR }\end{array}$ & $\begin{array}{l}-3.05 \pm 2.06 \\
+1.37 \pm 0.95 \\
(-11.25 \text { to }+4.75) \\
-0.87 \pm 0.85(0.00 \text { to }-6.00) \\
-0.06 \pm 0.06(0.3 \text { to }-0.18)\end{array}$ & $\begin{array}{l}-2.77 \pm 1.84 \\
+1.46 \pm 0.97 \\
(-11.00 \text { to }+4.75) \\
-0.78 \pm 0.72(0.00 \text { to }-6.00) \\
-0.07 \pm 0.05(0.3 \text { to }-0.3)\end{array}$ & $\begin{array}{l}<0.01 \\
0.15 \\
<0.01 \\
<0.01\end{array}$ \\
\hline $\begin{array}{l}\text { One-month postoperative data } \\
\text { Sphere, D } \\
\text { Cylinder, D } \\
\text { CDVA, logMAR } \\
\text { Binocular UDVA, logMAR }\end{array}$ & $\begin{array}{l}+0.05 \pm 0.43(+2.50 \text { to }-3.00) \\
-0.23 \pm 0.30(0 \text { to }-3.25) \\
-0.08 \pm 0.06(0.3 \text { to }-0.3) \\
-0.11 \pm 0.08(0.52 \text { to }-0.3)\end{array}$ & $\begin{array}{l}+0.07 \pm 0.39(+2.50 \text { to }-3.25) \\
-0.20 \pm 0.26(0 \text { to }-3.50) \\
-0.09 \pm 0.06(0.52 \text { to }-0.3) \\
-0.09 \pm 0.09(0.7 \text { to }-0.3)\end{array}$ & $\begin{array}{l}0.01 \\
<0.01 \\
<0.01 \\
<0.01\end{array}$ \\
\hline
\end{tabular}

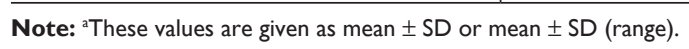

Abbreviations: CDVA, corrected distance visual acuity; UDVA, uncorrected distance visual acuity. 
Table 3 Preoperative and I-month postoperative clinical outcomes of refractive lens exchange patients

\begin{tabular}{|c|c|c|c|}
\hline \multirow[t]{2}{*}{ Clinical/demographic variable } & \multicolumn{2}{|l|}{ Consent type } & \multirow[t]{2}{*}{$P$-value } \\
\hline & In-clinic & Remote & \\
\hline Number of patients & $\mathrm{I}, 954$ & $\mathrm{I}, 800$ & - \\
\hline Female/male ratio & $46.6 \% / 53.4 \%$ & $46.9 \% / 53.1 \%$ & 0.86 \\
\hline $\mathrm{Age}^{\mathrm{a}}$ & $59.6 \pm 8.8(19-88)$ & $58.3 \pm 7.4(2 I-85)$ & $<0.01$ \\
\hline \multicolumn{4}{|l|}{ Preoperative data $^{a}$} \\
\hline \multicolumn{4}{|l|}{ Sphere, D } \\
\hline Myopic sphere & $-3.87 \pm 3.34$ & $-2.83 \pm 2.23$ & $<0.01$ \\
\hline Hyperopic sphere & $+2.44 \pm 1.69$ & $+2.37 \pm 1.44$ & 0.06 \\
\hline Range & $(-16.75$ to +10.75$)$ & $(-15.75$ to +10.25$)$ & \\
\hline Cylinder, D & $-0.79 \pm 0.74(0$ to -6.75$)$ & $-0.62 \pm 0.55$ (0 to -6.50$)$ & $<0.01$ \\
\hline CDVA, logMAR & $-0.02 \pm 0.09(0.3$ to -0.18$)$ & $-0.04 \pm 0.07(0.3$ to -0.18$)$ & $<0.01$ \\
\hline \multicolumn{4}{|l|}{ One-month postoperative data ${ }^{a}$} \\
\hline Sphere, D & $+0.03 \pm 0.51$ ( $(+2.00$ to -3.25$)$ & $+0.06 \pm 0.5$ I $(+2.50$ to -3.25$)$ & 0.003 \\
\hline Cylinder, D & $-0.45 \pm 0.44(0$ to -4.00$)$ & $-0.43 \pm 0.40(0$ to -4.00$)$ & 0.05 \\
\hline CDVA, logMAR & $-0.04 \pm 0.07$ (0.7 to -0.18$)$ & $-0.05 \pm 0.07(0.52$ to -0.3$)$ & $<0.01$ \\
\hline Binocular UDVA, logMAR & $-0.03 \pm 0.10(0.7$ to -0.18$)$ & $-0.04 \pm 0.10(0.6$ to -0.18$)$ & $<0.01$ \\
\hline
\end{tabular}

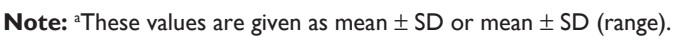

Abbreviations: CDVA, corrected distance visual acuity; UDVA, uncorrected distance visual acuity.

\section{One-month postoperative questionnaire}

In the LVC group, $97.5 \%$ of in-clinic patients and $98.3 \%$ of remote patients stated they were properly consented for surgery (question 3 ) and this slight difference was statistically significant $(P=0.04)$. Likewise, the percentages for the
RLE group were $97.6 \%$ for in-clinic and $97.9 \%$ for remote patients $(P=0.47)$.

Figure 1 depicts the postoperative satisfaction with vision (Table 1, question 4). At the 1-month postoperative aftercare visit, $94.0 \%$ of in-clinic and $94.7 \%$ of remote

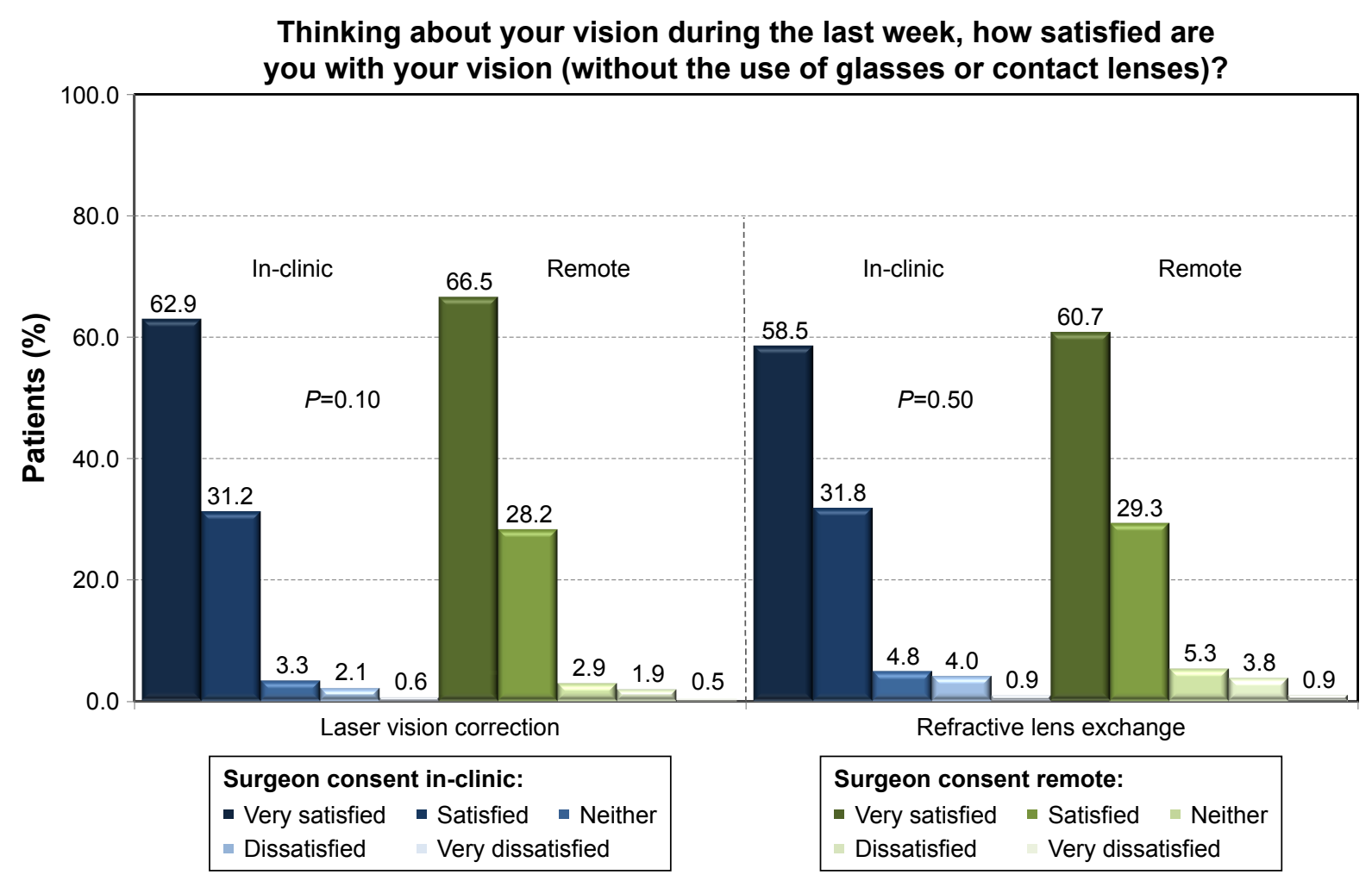

Figure I Postoperative satisfaction with visual acuity: patients who had a remote consent discussion with their surgeon vs patients who had a face-to-face discussion in the clinic. 
LVC patients were "satisfied" (very satisfied or satisfied) with their vision. For RLE patients, these percentages were $90.3 \%$ for the in-clinic group and $90.0 \%$ for the remote group. There was no statistically significant difference in postoperative satisfaction between the in-clinic and remote patients (Figure 1).

Of all LVC patients, $96.0 \%$ and $97.0 \%$ of in-clinic and remote patients, respectively $(P=0.05)$, were willing to recommend the surgery to their friends or relatives (question 5). These percentages were $94.7 \%$ for in-clinic and $95.3 \%$ for the remote group for RLE patients.

Table 4 summarizes the mean postoperative scores for optical side effects and dry eye (question 6). There was no statistically significant difference between in-clinic and remote patients in any questioned side effect, except for a slight difference in ghosting for LVC patients.

Figure $2 \mathrm{~A}$ and $\mathrm{B}$ shows the difficulties patients experienced with various activities (night driving, near vision, or distance tasks; questions 7-9 from Table 1). Again, no statistically significant difference was found in the outcomes of questions 7-9 between in-clinic and remote patients.

\section{Multivariate model}

Table 5 presents the outcomes of the regression model to predict the response to the question: "Do you feel you were properly consented for surgery?" RLE and LVC data were combined into one model to create a stronger data set. Initially, we explored two separate regression models for

Table 4 Visual phenomena and dry eyes

\begin{tabular}{l|l|l|l}
\hline $\begin{array}{l}\text { Postoperative } \\
\text { symptoms }\end{array}$ & \multicolumn{2}{l}{$\begin{array}{l}\text { Postoperative mean score } \\
\text { (mean } \pm \text { SD) }\end{array}$} \\
\cline { 2 - 4 } & In-clinic & Remote & P-value \\
\hline $\begin{array}{l}\text { Laser vision correction } \\
\text { Number of patients }\end{array}$ & 1,626 & 6,558 & \\
Starburst & $1.58 \pm \mathrm{I} .13$ & $\mathrm{I} .59 \pm \mathrm{I} .16$ & 0.75 \\
Glare & $1.65 \pm \mathrm{I} .14$ & $\mathrm{I} .67 \pm \mathrm{I} .16$ & 0.62 \\
Halo & $\mathrm{I} .57 \pm \mathrm{I} .12$ & $\mathrm{I} .55 \pm \mathrm{I} .10$ & 0.63 \\
Ghosting/double vision & $\mathrm{I} .34 \pm 0.93$ & $\mathrm{I} .25 \pm 0.79$ & 0.0006 \\
Dry eyes & $\mathrm{I} .96 \pm \mathrm{I} .3 \mathrm{I}$ & $\mathrm{I} .96 \pm \mathrm{I} .29$ & 0.99 \\
Refractive lens exchange & & & \\
Number of patients & $\mathrm{I}, 954$ & $\mathrm{I}, 800$ & \\
Starburst & $\mathrm{I} .85 \pm \mathrm{I} .4 \mathrm{I}$ & $\mathrm{I} .89 \pm \mathrm{I} .5 \mathrm{I}$ & 0.47 \\
Glare & $\mathrm{I} .96 \pm \mathrm{I} .40$ & $\mathrm{I} .96 \pm \mathrm{I} .48$ & 0.93 \\
Halo & $2.00 \pm \mathrm{I} .53$ & $2.00 \pm \mathrm{I} .58$ & $0.9 \mathrm{I}$ \\
Ghosting/double vision & $\mathrm{I} .35 \pm 0.93$ & $\mathrm{I} .37 \pm 0.99$ & 0.54 \\
Dry eyes & $\mathrm{I} .77 \pm \mathrm{I} .23$ & $\mathrm{I} .79 \pm \mathrm{I} .24$ & 0.60 \\
\hline
\end{tabular}

Note: Each patient rated visual phenomena/dry eye difficulties on a scale from I (= no difficulty) to 7 (= severe difficulty) and the mean score for all patients was calculated.
RLE and LVC, but the same predictive factors were found in both cases.

Question 4 (postoperative satisfaction with vision) was the major predictor of patient's perception of consent quality, and it was responsible for $80.4 \%$ of the variance explained by the regression model. Figure 3 shows the percentage of patients who were "very satisfied/satisfied", "neither satisfied nor dissatisfied", or "very dissatisfied/dissatisfied" with their postoperative visual outcomes for patients who felt consented properly, and those who did not feel properly consented. Of all patients who did not feel that they were properly consented for their refractive procedure, $32.5 \%$ were dissatisfied with the postoperative vision, while only $2.6 \%$ of patients were dissatisfied in the group of patients who indicated they were properly consented.

Postoperative visual phenomena $(5.8 \%$ variance explained, question 6 from Table 1) and dry eye symptoms $(1.0 \%$ variance explained) were the other statistically significant factors predicting the consent quality perception. Figure 4 shows the percentages of patients who had significant difficulties with postoperative glare, halos, starburst, ghosting/double vision, or dry eyes. Between $10.7 \%$ and $17.9 \%$ (depending on the type of phenomena) of patients who felt they were not properly consented for their procedure had severe postoperative difficulties with visual symptoms or dry eyes, whereas only between $0.7 \%$ and $2.3 \%$ of patients had significant difficulties in the group of patients who indicated they were "consented properly".

One month postoperative difficulties patients experienced with tasks described in questions 7-9 (night driving, near vision, and distance activities) had also a significant impact on consent quality perception and were responsible for $3.7 \%$ of the variance explained by the model. Figure 5 shows the percentage of patients who had a lot of difficulties or were unable to perform activities because of their vision. A significantly higher proportion of patients (up to $25.7 \%$ ) who were not satisfied with consent quality experienced postoperative difficulty with one of these tasks.

One-month postoperative binocular UDVA was also a significant predictor of consent satisfaction, accountable for $4.6 \%$ of the variance in our multivariate model. As an indication of this relationship, 93.5\% of all "consented properly" patients had postoperative binocular UDVA 20/20 or better, whereas this percentage was only $85.0 \%$ for patients who felt they were not properly consented.

Change between preoperative and postoperative CDVA had a very slight (1.5\% of the explained variance), but 

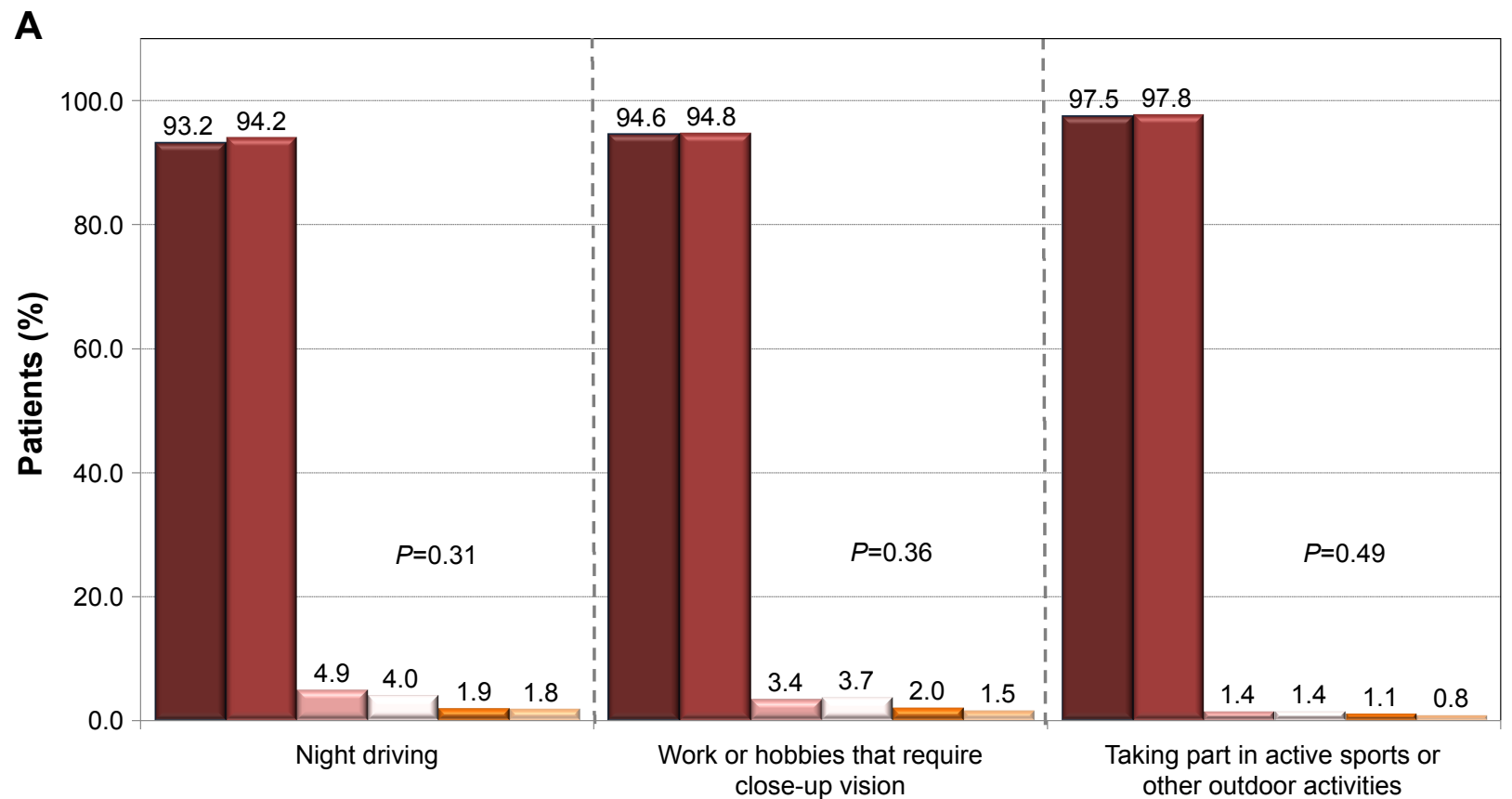

B

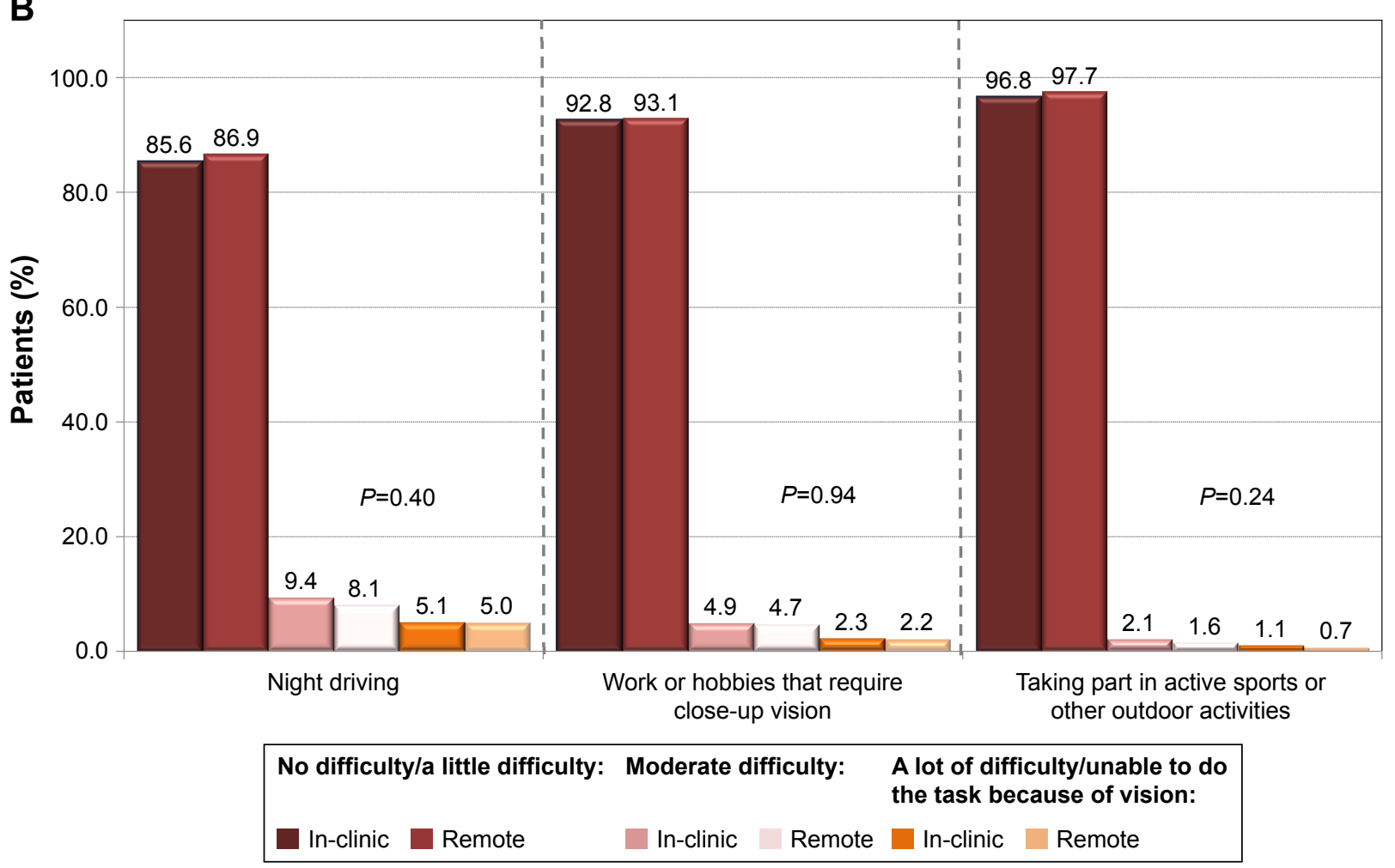

Figure 2 Postoperative difficulties with various tasks: patients who had a remote consent discussion with their surgeon vs patients who had a face-to-face discussion in the clinic. Notes: (A) Laser vision correction patients. (B) Refractive lens exchange patients.

statistically significant impact on the model. As little as $0.9 \%$ of all "consented properly" patients had CDVA reduced by $\geq 2$ lines at the 1-month postoperative visit in either eye and this number was $2.1 \%$ for patients who felt they were not properly consented.
Satisfaction with the surgeon's approach (questions 1 and $2,2.9 \%$ of the explained variance) was also a minor but statistically significant factor in the regression model. Of all the "consented properly" patients, $83.8 \%$ were "very satisfied" with the surgeon's care, while only $65.2 \%$ of patients 
Table 5 Results of multivariate regression analysis to predict outcomes of question 3: "Do you feel you were properly consented for surgery?" $\left(R^{2}=0.33, P<0.000\right.$ I $)$

\begin{tabular}{|c|c|c|c|}
\hline Independent variable & $\begin{array}{l}\text { Univariate, } \\
P \text {-value }\end{array}$ & $\begin{array}{l}\text { Multivariate, } \\
P \text {-value }\end{array}$ & $\begin{array}{l}\text { Model } \\
\text { contribution (\%) }\end{array}$ \\
\hline Age at treatment & $>0.05$ & - & - \\
\hline Gender & $>0.05$ & - & - \\
\hline Consent: in-clinic vs remote & $0.04 *$ & $>0.05$ & - \\
\hline Number of days between consent and surgery day & $>0.05$ & - & - \\
\hline Type of surgery (LVC or RLE) & $>0.05$ & - & - \\
\hline Preoperative sphere & $>0.05$ & - & - \\
\hline Preoperative cylinder & $>0.05$ & - & - \\
\hline Preoperative CDVA & $>0.05$ & - & - \\
\hline Postoperative sphere & $>0.05$ & - & - \\
\hline Postoperative cylinder & $0.0003^{*}$ & $>0.05$ & - \\
\hline Postoperative binocular UDVA & $<0.000 \mathrm{I}^{*}$ & $<0.000 I^{*}$ & 4.6 \\
\hline Change in CDVA & $<0.000 I^{*}$ & $0.003^{*}$ & 1.5 \\
\hline Day I surgeon care and questions (questions I and 2) & $<0.000 I^{*}$ & $<0.000 I^{*}$ & 2.9 \\
\hline Month I satisfaction (question 4) & $<0.000 I^{*}$ & $<0.000 I^{*}$ & 80.4 \\
\hline Month I impact of eyesight on various activities (questions 7-9) & $<0.0001 *$ & $<0.000 I^{*}$ & 3.7 \\
\hline Month I dry eyes (question 6) & $<0.000 I^{*}$ & $0.01 *$ & 1.0 \\
\hline Month I visual symptoms (starburst, glare, halo, ghosting/double vision; question 6) & $<0.000 I^{*}$ & $<0.000 I^{*}$ & 5.8 \\
\hline
\end{tabular}

Note: *Statistically significant.

Abbreviations: CDVA, corrected distance visual acuity; LVC, laser vision correction; RLE, refractive lens exchange; UDVA, uncorrected distance visual acuity.

were "very satisfied" in the group of "not consented properly" patients. A similar relationship was observed in question 2: $82.5 \%$ of "consented properly" patients and $61.7 \%$ of "not consented properly" patients were "very satisfied" with their surgeon answering all their questions.

The type of consent (in-clinic vs remote) was a statistically significant factor in the univariate model, with in-clinic patients being less satisfied with the consent process compared to remote patients. However, consent type had no impact on the patient's perception of consent quality in the multivariate model.

\section{Discussion}

In our study population, the majority of LVC patients and approximately half of the RLE patients preferred a telemedicine consent approach with their surgeon. Remote

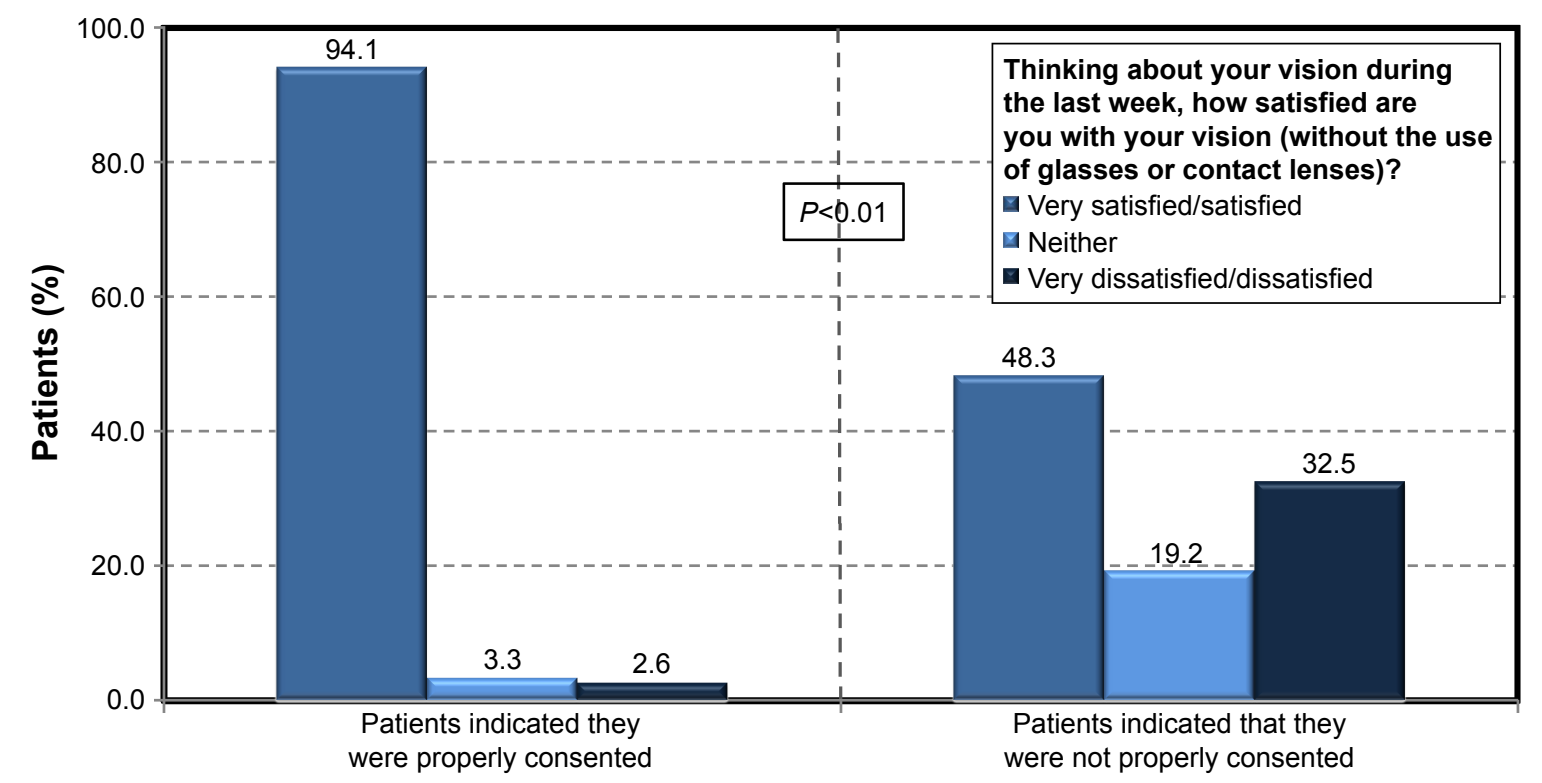

Figure 3 Postoperative satisfaction with visual acuity for patients who felt they were properly consented for surgery and those who did not feel so. 


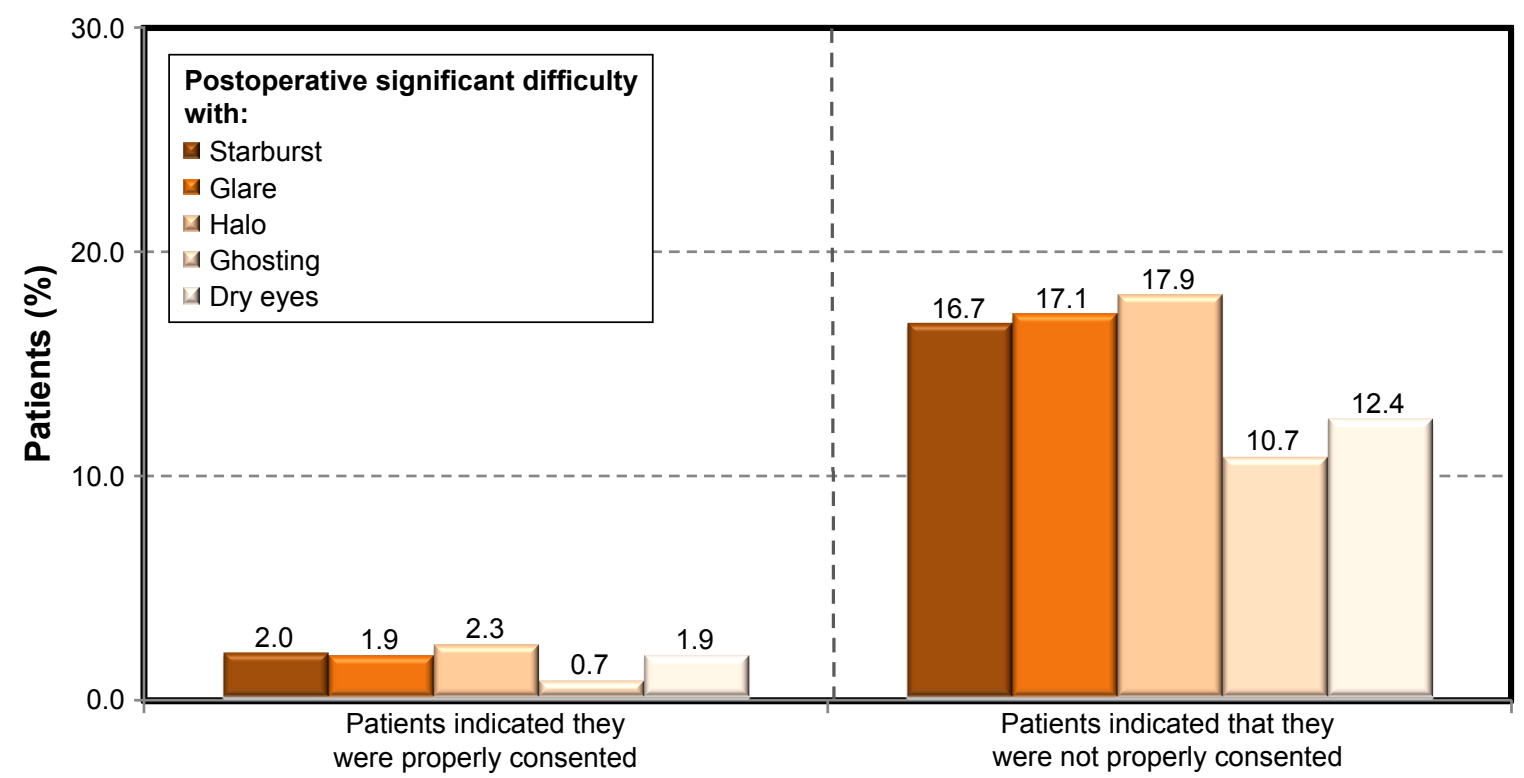

Figure 4 Postoperative difficulties with optical side effects compared between patients who indicated they were "properly consented" vs those who indicated they were "not properly consented" for their refractive procedure. "Significant difficulty": patients who scored 6 or 7 on a scale between I (= no difficulty) and 7 (= severe difficulty).

consenting has many advantages for both - surgeon and the patient. Surgeons can provide consultations with flexible timetables and locations, even from the comfort of their home. ${ }^{2,10}$ Furthermore, teleophthalmology can provide significant savings in time and travel expenses for patients, which could be the reason why it was mostly preferred by the younger population of patients, who may have busier schedules. Previous studies found good agreement between the diagnosis and management decisions by teleophthalmology compared to the diagnosis and management decisions in eye clinics. ${ }^{2,5,6,11,12}$
This is mostly because diagnostic imaging and measurements play an important role in ophthalmology $y^{4}$ and these can be easily transferred via telemedicine and help in making a diagnosis or deciding on the suitability of candidates for surgery. In our consenting approach, however, the patient is always clinically examined by an ophthalmologist and the final decision to proceed with surgery is always made by the treating surgeon.

In this study, we compared satisfaction of patients who opted for the telemedicine approach and those who preferred

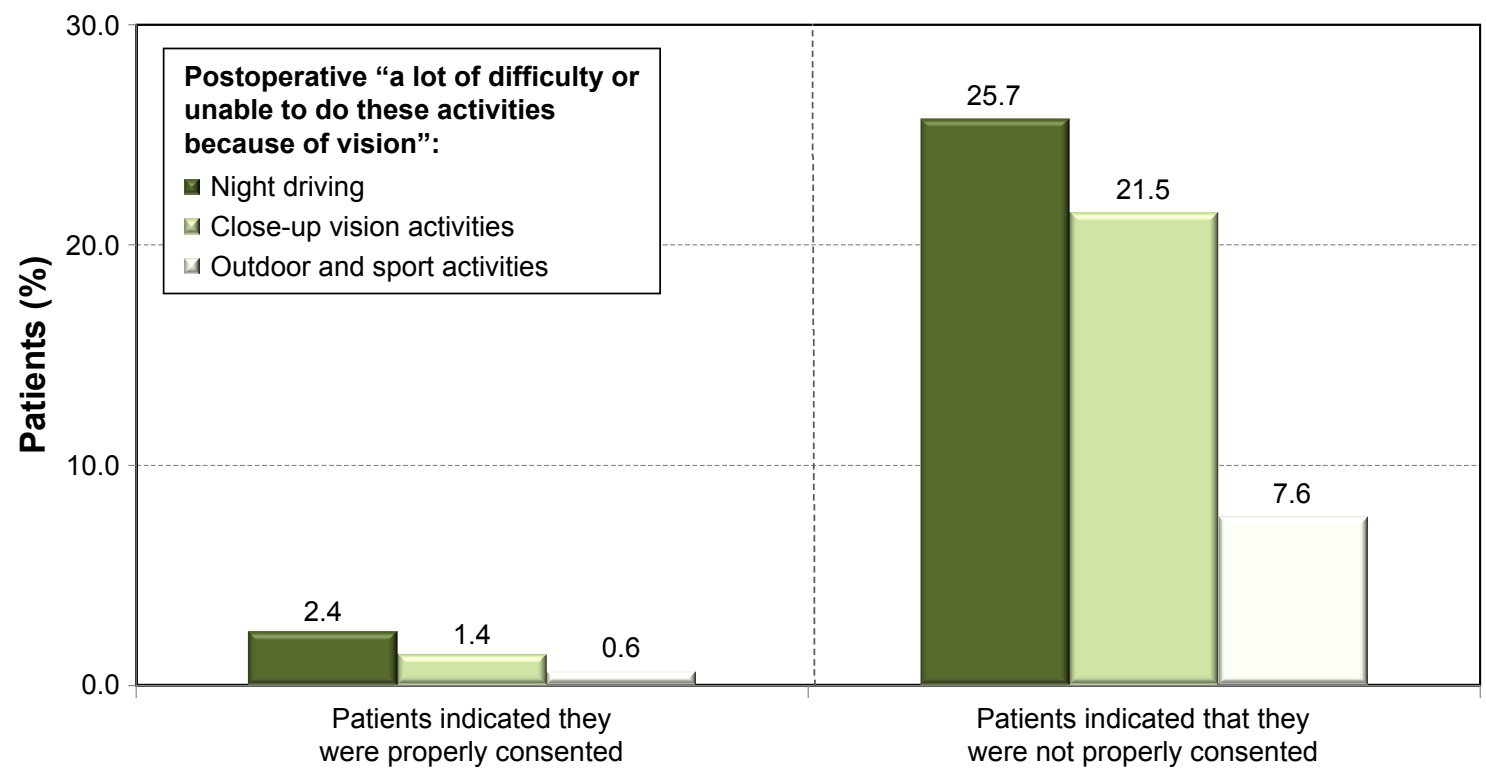

Figure 5 Postoperative visual difficulties with various tasks based on patient's perception of consent quality. 
to meet their surgeon personally ahead of the surgery day. We found similar satisfaction with the consent process. In the LVC group, $97.5 \%$ of in-clinic patients and $98.3 \%$ of remote patients indicated that they were properly consented for surgery $(P=0.04)$. In the RLE group, $97.6 \%$ of in-clinic and $97.9 \%$ of remote patients stated their consent process for surgery was adequate $(P=0.47)$. The slight statistically significant difference in the LVC group is most likely due to the difference in clinical data between the two groups (eg, inclinic patients were slightly older and had more challenging preoperative refractive errors), which is the reason why it is necessary to apply a multivariate model to find real factors affecting satisfaction with consent quality.

Similar to our previous publication, ${ }^{8}$ we found that the major factor leading to dissatisfaction with consent quality is not the actual consent type, but an unsatisfactory outcome. The major factor affecting perception of consent quality was the satisfaction with postoperative vision, and it was responsible for $80.4 \%$ of the variance explained by our multivariate model. Of all "not consented properly" patients, $32.5 \%$ were dissatisfied with vision, whereas as little as $2.6 \%$ of patients were dissatisfied with vision if they felt their consent process was adequate. Other, also statistically significant, factors in the model were difficulties with postoperative visual phenomena, dry eyes, difficulties with tasks related to night driving, distance and close-up vision, postoperative binocular UDVA, and change in CDVA. All these suggest that an unsatisfactory postoperative outcome leads patients to believe that they were not properly consented. Satisfaction with surgeon care and surgeons answering questions was also a minor, but statistically significant factor in the model (2.9\% of the explained variance); however, the type of consent (remote or in-clinic) had no effect on the patient's perception of consent quality. It is also important to note that there were patients who were satisfied with their visual outcomes but dissatisfied with the consent process. These were perhaps patients who were genuinely dissatisfied with their consent due to a combination of various factors (such as delay in getting an appointment, unhappy with the surgeon's approach, unhappy with service received from the local clinic, long waiting time in the clinic), but still appreciated the visual gain from their refractive surgery. However, the proportion of patients who were dissatisfied with the consent process in our cohort was small $(\sim 2 \%$ of all patients included in this study).

Inadequate consenting process has been cited as a major factor in ophthalmology malpractice suits, ${ }^{13-17}$ but it is hardly ever the primary cause of litigation. ${ }^{18}$ It is the poor outcome that primarily leads to litigation in ophthalmology, with the consent process being a secondary factor in claims. Patients have been shown to process information selectively and tend to retain only the facts that are in favor of their decision to proceed with surgery. ${ }^{19-21}$ They often disregard or even deny hearing the risks and adverse events associated with their refractive surgery. ${ }^{19-21}$ To help address this issue, various forms of consenting tools have been proposed to improve the retention of consent information. These mostly consist of a combination of written, verbal, and audiovisual information ${ }^{22-28}$ and can significantly contribute to patients understanding of their medical condition and the proposed surgical procedures. ${ }^{29-33}$

The consenting process discussed here is multistep and involves written, spoken, and audiovisual delivery of the risks, benefits, and alternatives of surgery. Patients first see a refractive optometrist in their local clinic and have a discussion regarding potential procedures. They then watch a video, which reiterates the information provided by the optometrist, and are provided a written consent form. During the telephone discussion, the surgeon again discusses the risks and benefits of surgery, reviews the information recorded by the optometrist, ensures that the patient can provide informed consent, and answers all questions. The consent process culminates in signing the consent form, where the points of discussion are reiterated, and the patient confirms an understanding of the presented information.

Based on our multivariate model outcomes, we believe that a telemedicine surgeon discussion is essentially equivalent to a face-to-face approach. In fact, telemedicine consenting is increasingly used in various fields of medicine $\mathrm{e}^{34,35}$ and results in high patient satisfaction and significant cost and time savings. Teleconsent was found to combine the convenience and accessibility of obtaining consent remotely with the confidence and value of in-person approach. ${ }^{34}$ Previous studies found no differences in comprehension and patientreported understanding when comparing telemedicine and face-to-face approaches for delivering informed consent. ${ }^{35}$

Our study has a few limitations. It is retrospective and the regression model is based on 1-month outcomes, when the healing process may not be completed in all patients. It is also possible that most of the symptoms and side effects subside over time and both CDVA and UDVA improve. For that reason, patients might change their opinion about consent and satisfaction with vision at later follow-ups. However, we feel it is appropriate to ask patients about their experience with the consenting process at early follow-ups, which are attended by the majority of patients. Another 
advantage of using a 1-month postoperative questionnaire is that patients already experience outcomes of their procedure, but still have some recollection of their preoperative consent information. The questionnaire we used in our study has been previously successfully used in many large population studies. ${ }^{8,36-38}$ Another possible limitation of the study is the bias in patient's selection of consent type. There might have been lots of factors that affected the patient's decision to proceed with remote consent, such as work commitments, lifestyle, geographical distance from the nearest clinic, etc. However, the number of patients dissatisfied with the consent process was so low in this study that we believe our consent process (regardless of the type) is adequate and comprehensive.

\section{Conclusion}

In conclusion, we believe that remote consenting when utilized as part of a multimodal consent approach for elective refractive surgery can provide patients with an equivalent quality of information as meeting the surgeon personally before the day of their procedure. The telemedicine approach to consenting was eagerly accepted by patients and resulted in high satisfaction. As previously suggested in the literature, a perceived poor outcome is the major cause of dissatisfaction with the consenting process. Reiterating the risks and increasing the patient's understanding of surgery is one of the most important steps in consenting for elective procedures.

\section{Disclosure}

Steven C Schallhorn is a chief medical officer for Carl Zeiss Meditec and a chairman of the medical advisory board for Optical Express. The authors report no other conflicts of interest in this work.

\section{References}

1. Voran D. Telemedicine and beyond. Mo Med. 2015;112(2):129-135.

2. Labiris G, Panagiotopoulou EK, Kozobolis VP. A systematic review of teleophthalmological studies in Europe. Int J Ophthalmol. 2018;11(2): 314-325.

3. Ekeland AG, Bowes A, Flottorp S. Effectiveness of telemedicine: a systematic review of reviews. Int J Med Inform. 2010;79(11):736-771.

4. Ayatollahi H, Nourani A, Khodaveisi T, Aghaei H, Mohammadpour M. Teleophthalmology in practice: lessons learned from a pilot project. Open Med Inform J. 2017;11:20-28.

5. Bartnik SE, Copeland SP, Aicken AJ, Turner AW. Optometry-facilitated teleophthalmology: an audit of the first year in Western Australia. Clin Exp Optom. 2018;101(5):700-703.

6. Gupta SC, Sinha SK, Dagar AB. Evaluation of the effectiveness of diagnostic \& management decision by teleophthalmology using indigenous equipment in comparison with in-clinic assessment of patients. Indian J Med Res. 2013;138(4):531-535.
7. Kozak I, Payne JF, Schatz P, Al-Kahtani E, Winkler M. Teleophthalmology image-based navigated retinal laser therapy for diabetic macular edema: a concept of retinal telephotocoagulation. Graefes Arch Clin Exp Ophthalmol. 2017;255(8):1509-1513.

8. Schallhorn SC, Hannan SJ, Teenan D, Schallhorn JM. Role of the treating surgeon in the consent process for elective refractive surgery. Clin Ophthalmol. 2016;10:2391-2402.

9. General Medical Council. Guidance for doctors who offer cosmetic interventions. 2016. Available from: https://www.gmc-uk.org/-/ media/documents/Guidance_for_doctors_who_offer_cosmetic_ interventions_210316.pdf_65254111.pdf. Accessed November 18, 2018.

10. Kumar S, Yogesan K. Internet-based eye care: VISION 2020. Lancet. 2005;366(9493):1244-1245.

11. Maa AY, Patel S, Chasan JE, Delaune W, Lynch MG. Retrospective evaluation of a teleretinal screening program in detecting multiple nondiabetic eye diseases. Telemed J E Health. 2017;23(1): $41-48$.

12. Whited JD. Accuracy and reliability of teleophthalmology for diagnosing diabetic retinopathy and macular edema: a review of the literature. Diabetes Technol Ther. 2006;8(1):102-111.

13. Ali N, Little BC. Causes of cataract surgery malpractice claims in England 1995-2008. Br J Ophthalmol. 2011;95(4):490-492.

14. Bhan A, Dave D, Vernon SA, et al. Risk management strategies following analysis of cataract negligence claims. Eye. 2005;19(3): 264-268.

15. Mavroforou A, Michalodimitrakis E. Physicians' liability in ophthalmology practice. Acta Ophthalmol Scand. 2003;81(4):321-325.

16. Santos W, Solari HP, Ventura MP. [Litigation in ophthalmology: analysis of possible triggers]. Arq Bras Oftalmol. 2010;73(6): 501-504.

17. Steven Bailey C, Bailey JA. Claims of alleged medical negligence in refractive surgery: causes and avoidance. Cont Lens Anterior Eye. 2007; 30(2):144148-147149; quiz 148-149.

18. Kiss CG, Richter-Mueksch S, Stifter E, Diendorfer-Radner G, VelikayParel M, Radner W. Informed consent and decision making by cataract patients. Arch Ophthalmol. 2004;122(1):94-98.

19. Guerin M, O'Keeffe M. Informed consent in refractive eye surgery: learning from patients and the courts. Ir Med J. 2012;105(8): 282-283.

20. Dhingra N, Clews S, Neugebauer MA, Hubbard AD. What patients recall of the preoperative discussion before cataract surgery: results of a questionnaire survey. Eye (Lond). 2004;18(8):790-791.

21. Priluck IA, Robertson DM, Buettner H. What patients recall of the preoperative discussion after retinal detachment surgery. Am JOphthalmol. 1979;87(5):620-623.

22. Schenker Y, Fernandez A, Sudore R, Schillinger D. Interventions to improve patient comprehension in informed consent for medical and surgical procedures: a systematic review. Med Decis Making. 2011;31(1): 151-173.

23. Abbott RL. Informed consent in refractive surgery. Curr Opin Ophthalmol. 1998;9(4):29-34.

24. Stacey D, Légaré F, Lewis K, et al. Decision aids for people facing health treatment or screening decisions. Cochrane Database Syst Rev. 2017;4:CD001431.

25. Brown H, Ramchandani M, Gillow JT, Tsaloumas MD. Are patient information leaflets contributing to informed consent for cataract surgery? J Med Ethics. 2004;30(2):218-220.

26. Moseley TH, Wiggins MN, O'Sullivan P. Effects of presentation method on the understanding of informed consent. Br J Ophthalmol. 2006;90(8):990-993.

27. Wollinger $\mathrm{C}$, Hirnschall N, Findl O. Computer-based tutorial to enhance the quality and efficiency of the informed-consent process for cataract surgery. J Cataract Refract Surg. 2012;38(4):655-659.

28. Shukla AN, Daly MK, Legutko P. Informed consent for cataract surgery: patient understanding of verbal, written, and videotaped information. J Cataract Refract Surg. 2012;38(1):80-84. 
29. Heil H, Struck J. Multimediale Lernsystem als Ausbildungsintrumente [Multimedia learning systems as a training instrument]. In: Dette K, Haupt D, Polze C, editors. Multimedia Und Computeranwendungen in Der Lehre: 6 [Multimedia learning systems as a training instrument: 6]. CIP-Kongress, Berlin, 6-8 Oktober, 1992. Berlin, Germany: Springer Verlag; 1992:40-47. German.

30. Wilson EA, Park DC, Curtis LM, et al. Media and memory: the efficacy of video and print materials for promoting patient education about asthma. Patient Educ Couns. 2010;80(3):393-398.

31. Murphy PW, Chesson AL, Walker L, Arnold CL, Chesson LM. Comparing the effectiveness of video and written material for improving knowledge among sleep disorders clinic patients with limited literacy skills. South Med J. 2000;93(3):297-304.

32. Wang DS, Jani AB, Sesay M, et al. Video-based educational tool improves patient comprehension of common prostate health terminology. Cancer. 2015;121(5):733-740.

33. Kandula NR, Nsiah-Kumi PA, Makoul G, et al. The relationship between health literacy and knowledge improvement after a multimedia type 2 diabetes education program. Patient Educ Couns. 2009;75(3):321-327.
34. Welch BM, Marshall E, Qanungo S, et al. Teleconsent: a novel approach to obtain informed consent for research. Contemp Clin Trials Commun. 2016;3:74-79.

35. Bobb MR, van Heukelom PG, Faine BA, et al. Telemedicine provides noninferior research informed consent for remote study enrollment: a randomized controlled trial. Acad Emerg Med. 2016;23(7):759-765.

36. Schallhorn SC, Venter JA, Hannan SJ, Hettinger KA, Teenan D. Effect of postoperative keratometry on quality of vision in the postoperative period after myopic wavefront-guided laser in situ keratomileusis. J Cataract Refract Surg. 2015;41(12):2715-2723.

37. Brown MC, Schallhorn SC, Hettinger KA, Malady SE. Satisfaction of 13,655 patients with laser vision correction at 1 month after surgery. J Refract Surg. 2009;25(7 Suppl):S642-S646.

38. Venter JA, Pelouskova M, Collins BM, Schallhorn SC, Hannan SJ. Visual outcomes and patient satisfaction in 9366 eyes using a refractive segmented multifocal intraocular lens. J Cataract Refract Surg. 2013; 39(10):1477-1484.
Clinical Ophthalmology

\section{Publish your work in this journal}

Clinical Ophthalmology is an international, peer-reviewed journal covering all subspecialties within ophthalmology. Key topics include: Optometry; Visual science; Pharmacology and drug therapy in eye diseases; Basic Sciences; Primary and Secondary eye care; Patient Safety and Quality of Care Improvements. This journal is indexed on

\section{Dovepress}

PubMed Central and CAS, and is the official journal of The Society of Clinical Ophthalmology (SCO). The manuscript management system is completely online and includes a very quick and fair peer-review system, which is all easy to use. Visit http://www.dovepress.com/ testimonials.php to read real quotes from published authors. 